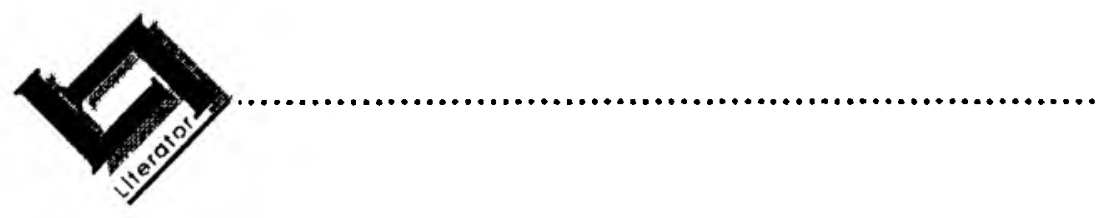

\title{
Funkslonele meertaligheid in Suid-Afrika: 'n onbereikbare ideaal?
}

\author{
Marlene Verhoef \\ Departement Tale \\ Vaaldriehoekkampus \\ Potchefstroomse Unlversitelt vir $\mathrm{CHO}$ \\ VANDERBIJLPARK \\ E-pos: aftmmv@puknet.puk.ac.za
}

\section{Abstract}

Functianal multilingualism in South Afrlca: an unattainable ideal?

Although much has been done on an official level to establish true multilingualism in South Africa, a tendency towards English monolingualism seems to exist in the country. The aim of this article is to describe the official stipulations in pursuit of multilingualism, as they appear in the Constitution (Act 108 of 1996), the School Act (Act 84 of 1996) and the final report of Langtag. In addition to the present demands, the article also responds to previous demands for multilingualism in the South African context, particularly as stated in the Bantu Education Act of 1953. It is argued that, because of the negative connotations associated with mothertongue instruction in the past, contemporary mother-tongue instruction will also be contaminated.

Apart from the theoretical investigation into multilingualism, the article reports on empirical research that has been done in this regard in the North West Province where the attitudes and perceptions of the school population towards the regional languages were measured. Although the subjects reacted positively to the official status granted to several South African languages, they expressed a preference for English as working language because of the access it gives to personal, economic and social development and empowerment. The article concludes with brief recommendations regarding language planning opportunities that derive from this situation. 


\section{Kontekstuallsering en probleemstelling}

Edwards (1994:8-11) beweer dat tale se welsyn grootliks bepaal word deur maatskaplike en kulturele motiverings en nie soseer deur wetmatighede nie. Hy impliseer dat, indien navorsing gedoen word oor die hantering van taalsake op onderwysdomein, lig gewerp kan word op die interaksie tussen die amptelike taalbeleid en makro sosiale dryfvere wat die implementering van sodanige taalbeleid beïnvloed.

Met die ponering van hierdie aanname teen die agtergrond van die grootskaalse politieke en sosiale verandering wat sedert 1990 in Suid-Afrika plaasgevind het, word dit uit die hantering van onderwystaalsake in die post-apartheidsbedeling duidelik dat die bevordering van meertaligheid en die kweek van respek vir die talediversiteit basiese grondbeginsels vorm vir die uitvoering van die taalartikels in die grondwet (Langtag, 1996b:211).

Belangwekkende amptelike uitsprake met betrekking tot taalkwessies in die onderwys is gemaak in onder andere die onderwyswitskrifte van 1995 en 1996, die sogenaamde Hunterverslag van 1996 en die verslae van die Nasionale Kommissie op Hoër Onderwys en Langtag (albei in 1996). Ook het die totstandkoming en werksaamhede van Pansat (1996), die promulgering van die Suid-Afrikaanse Skolewet, die inwerkingtreding van die nuwe nasionale Grondwet (Wet 108 van 1996), die aankondiging van Kurrikulum 2005, sodanige vérreikende implikasies dat taalbeplanners beslis móét kennisneem van dit wat met betrekking tot taalsake in onderwysgeledere aangaan.

Dit staan bo alle twyfel vas dat die onderwyssituasie direk belang het by die nasionale taalbeleid, omdat die onderwys, wêreldwyd, die terrein is waar alle nasionale taalbeleide in werking gestel word. Dit is van besondere belang vir Suid-Afrika omdat die onderwyssituasie, by wyse van wetgewing, die kontakpunt gemaak word vir die veelheid tale en kulture, en as sodanig dié fokus vorm waarin funksionele meertaligheid sy beslag moet kry.

By 'n noukeurige waarneming van die Suid-Afrikaanse taalsituasie oor die algemeen, spesifiek met betrekking tot die bevordering van meertaligheid, lyk dit of daar moontlik spanning bestaan tussen die makro-taalplan en die implementering daarvan op mikro-vlak. Hierdie waarneming word veral empiries bevestig uit die aanduidings op grondvlak dat die breë Suid-Afrikaanse bevolking nie so gretig is as wat aanvanklik gemeen is om meertaligheid op alle samelewingsvlakke te vestig nie, hoewel dit amptelik oënskynlik ' $n$ hoëprioriteitsaak is (Beukes, 1996:156; Buthelezi, 1996:49; Verhoef, 1996). Dié onderwaardering 
en miskenning van funksionele meertaligheid ${ }^{1}$ word hoofsaaklik gewyt aan taalgemeenskappe se gevestigde, gestereotipeerde taalpersepsies wat onder andere lei tot ' $n$ neiging tot eentaligheid in die heersende taalpraktyk.

Die waargenome taalprobleem kry egter 'n ander dimensie wanneer dit geïnterpreteer word teen die agtergrond van wat Edwards (1994:176) sê: hy voer aan dat die grondwetlike erkenning van meertaligheid dikwels bloot gemotiveer word deur politieke dwang 2 en dat die ponering van meertaligheid in taalbeleide nie noodwendig dui op die werklike intrinsieke waarde wat per se aan meertaligheid as verskynsel geheg word nie. Die toets vir die meertalige SuidAfrikaanse taalbeleid lê dus daarin om te bepaal of die grondwetlike bereëling van 'n meertalige samelewing (soos dit uit die nasionale wetgewing na vore kom) of spruit uit politieke dwang, of gemotiveer is uit 'n opregte begeerte om 'n samelewing tot stand te bring waarin die veelheid tale en kulture as nasionale bates gesien word. Ook sê Edwards (1994:176-7) dat dit nie bo alle twyfel bewys kan word dat wetgewing oor die bevordering van multitaligheid bo alle twyfel nie net maar lippetaalpogings is nie. En indien dit dalk nié is nie, gebeur dit dikwels dat daar nie-amptelike druk bestaan om taaldiversiteit teen te werk.

Hierdie siening werp in die besonder lig op die Suid-Afrikaanse taalsituasie omdat dit, ten spyte van openlike regeringsbeleid, duidelik word dat daar 'n duidelike tendens en openlike aandrang tot Engelse eentaligheid bestaan. In die woorde van Edwards (1994) kan die vraag dus met reg gevra word of dit nie hier in Suid-Afrika dalk gaan om lippetaalbevordering van meertaligheid wat bloot spruit uit politieke dwang nie.

\section{Doel}

Die oorhoofse doel van hierdie artikel is om die meertaligheidskwessie onder die vergrootglas te plaas en spesifiek aandag te gee aan die grondwetlike eis om die vestiging en uitbouing van meertaligheid én die persepsies hierteenoor, soos dit in 'n taaloudit wat in 1996 onder die skoolbevolking van die Noordwesprovinsie onderneem is, na vore gekom het. Uiteindelik is die besondere doel hiermee om te bepaal in watter mate die bree taalpubliek algemene eienaarskap het in die meertaligheidsidee en watter kritiese suksesfaktore geidentifiseer kan word vir die optimale implementering van 'n meertalige taalbeleid. Hierdie kritiese

1 Funksionele meertaligheid verwys na 'n meertalige situasie waarin ' $n$ veelheid tale as hosfunksietale gebruik word, dit wil sê waarin daar nie op diglossiese wyse met tale omgegaan word nic.

2 Die politicke dwang dui daarop dat die taalbeleid gemotiveer is deur blote politiese korrektheid en nie soseer daardeur dat beleidstellers oortuig is van die intrinsieke waarde van die beleid nie. 
evaluering van die makro- en mikro-taalopset in Suid-Afrika is van kardinale belang vir sowel taalbeplanners en taalpraktisyns, as vir politieke en onderwysbeleidmakers, omdat dit verreikende en rigtinggewende invloed behoort te hê op die voortgaande taalbeplanningsproses in die land.

\section{Die grondwetlike eise om meertaligheid}

Die finale Grondwet (Wet 108 van 1996) van die Republiek van Suid-Afrika erken taal as grondbeginsel (Artikel 6) en die reg op vrye taalkeuse in Artikels 9(3), 29(2), 30 en 31 gee daaraan erkenning as fundamentele reg. Daarbenewens is dit by implikasie duidelik dat dié taalbepalings, soos vervat in Hoofstuk 1 en 2 van die Grondwet, verstaan moet word teen die agtergrond van Artikels 7(1), 8(1) en $8(2)$. Artikels $7(1),(8) 1$ en $8(2)$ stipuleer dat die Handves van Regte beskerming verleen aan álle Suid-Afrikaners, dat die demokratiese waardes van menswaardigheid, gelykheid en vryheid bevestig word en dat alle wetgewende liggame, asook alle natuurlike en regspersone in die land deur die wet aan die Handves onderwerp word. Nie alleen skep dié artikels in die Handves van Regte die konteks vir die verstaan van die taalartikels nie, maar word ook by implikasie aangedui dat die welsyn van alle tale binne die meertalige Suid-Afrikaanse situasie daardeur beskerm word.

Die taalartikels in die Grondwet is pertinent daarop gerig om veeltaligheid te erken, te beskerm en te ontgin, om die veelheid Suid-Afrikaanse tale op gelykwaardige en billike wyse te behandel en om die hegemonie van enige enkele taal, en daarmee saam eentaligheid, op alle regeringsvlakke te verwerp.

Dit word allerweë erken dat dié taalbeleid in wese behoort te verseker dat daar optimale erkenning en uitoefening van meertalige taalregte in Suid-Afrika behoort te wees (Steyn, 1996:274).

Die aanhef tot die Suid-Afrikaanse Skolewet (Wet 84 van 1996) sê ook duidelik dat een van die motiverings van dié wet juis is dat die verskeidenheid kulture en tale in Suid-Afrika beskerm en bevorder moet word.

Daarby word dit uit die verslag van die Langed-subkomitee van Langtag duidelik dat die bevordering en gebruik van álle tale in Suid-Afrika nasionale eenheid en kohesie in die oog moet hê, dat die nasionale onderwystaalbeleid meertaligheid mót bevorder en dat leerders se huistale/primêre tale/eerste tale as onderrigmediums binne 'n paradigma van byvoegende meertaligheid gebruik moet word met inagneming van die keuse van ouers, onderwysers en leerders en hul gesindhede daarteenoor (Langtag, 1996a: 124).

Ten spyte van dié bepalings kom dit voor of meertaligheid nie grond raak in die Suid-Afrikaanse samelewing nie - trouens, ondanks amptelike meertaligheid, 
manifesteer die tendens tot 'n eentalige Engelse samelewing al hoe duideliker in alle vlakke van die samelewing.

Wanneer die taalbeplanningsproses waardeur dié amptelike taalbeleid tot stand gekom het, krities onder die vergrootglas geplaas word, begin dit duidelik word waarom die gaping tussen die teoretiese beplanningsfase en die praktiese implementeringsfase so groot lyk: dit kom voor of die inisiatief, wat as 'n tipiese gedesentraliseerde taalbeplanningsproses begin het, oorgegaan het in 'n implementeringsfase wat hoofsaaklik op gesentraliseerde beginsels geskoei is.

Nie alleen is die vertrekpunte van hierdie twee paradigmas heeltemal verskillend nie, hulle metodes en uiteindelike doelwitte verskil ook heelwat (Tollefson, 1981:176). Die wese van gedesentraliseerde taalbeplanning lê in die feit dat taalgemeenskappe oor besluitnemingsbevoegdheid beskik met betrekking tot die opstel, implementering en omvang (sy dit nasionaal, provinsiaal of plaaslik) van enige taalbeleid. Hierdie benadering verseker dat die taalgemeenskap op wie die taalbeplanning gerig is, eienaarskap in die hele proses verkry. Daarteenoor word gesentraliseerde taalbeplanningsprosesse gekenmerk deur primêre inspraak deur gesagsinstansies soos regerings, besture en direksies van instellings en maatskappye in die prioriteitsbepaling, opstel en implementering van taalbeleide.

Toegepas op die opstel en implementering van die veeltalige taalbeleid in SuidAfrika word dit duidelik dat die aanloop en beplanningsfases hiervan deur gedesentraliseerde beginsels gerig is omdat die formulering van die beleid onder andere gerig is deur wye inspraak uit alle taalgemeenskappe. Daarteenoor word dit, reeds sedert die totstandkoming van die beleid, uit die hantering van taalsake op verskillende terreine uit die Suid-Afrikaanse samelewing duidelik dat die implementering van die beleid hoofsaaklik op streng gestruktureerde en voorskriftelik gesentraliseerde beginsels geskied: let ter illustrasie op die feit dat verskeie instellings en organisasies sedert 1994 op hul eie besluit het om voorkeurbehandeling aan Engels te gee ten spyte van die meertalige samelewingsverbande waarin dié instellings funksioneer.

Hierdie oënskynlike onderbreking in die taalbeplanningsdinamiek waarin die energieke gedesentraliseerde taalbeplanningsinisiatief oorgegaan het tot 'n implementeringsfase wat hoofsaaklik op gesentraliseerde beginsels geskoei is, is grootliks verantwoordelik vir die feit dat daar nie aan die gestelde verwagtinge van die taalbeleid voldoen word met die inwerkingstelling daarvan nie.

Dit word ook duidelik uit die omringende sosio-politieke omgewing, waarin hierdie taalbeleid geimplementeer word dat sekere heersende politieke dryfvere 'n bepalende invloed uitoefen daarop: volgens Steyn (1996:275) bring die beleid van regstellende aksie en die ideologie van nasiebou mee dat Engels ten koste van alle ander tale in Suid-Afrika bevoordeel word. Vervolgens is dit nood- 
saaklik dat daar oor die hele breë maatskaplike en politieke spektrum heen instemming, toewyding en eienaarskap in die taalbeleid gekry moet word, sodat dit die noodsaaklike dinamika kan verleen in die uiteindelike uitvoering daarvan.

Die vraag wat daarom met reg gevra kan word, is of die meertalige taalbeleid soos dit grondwetlike vergestalting in Wette 108 en 84 van 1996 gekry het, nie dalk werklik daar staan ter wille van politieke dwang en korrektheid nie. Andersyds kan, vanweè 'n verskeidenheid redes, die knoop dalk lê by 'n algemene onbetrokkenheid en gebrek aan eienaarskap by die taalgemeenskap in die breë.

\section{Die bevordering van meertaligheid in die Suid- Afrikaanse onderwysstelsel}

Een van die kernaanbevelings van Langtag (1996a) ten opsigte van die totstandbrenging van 'n meertalige onderwysstelsel is dat leerders se huistale as onderrigmedium gebruik moet word binne 'n paradigma van byvoegende meertaligheid met inagneming van die keuse van ouers, onderwysers en leerders en hul gesindhede daarteenoor (Langtag, 1996a:124).

Hoewel daar met die eerste oogopslag etlike praktiese probleme geopper kan word vir die gebruik van die huistale van alle leerders in Suid-Afrika as onderrigmediums, lyk dit of die vernaamste struikelblok waarskynlik mag lê by die inagneming van die keuse van ouers, onderwysers en leerders en hul gesindhede daarteenoor.

Hoewel daar waarskynlik ook vir hierdie gesindheidsprobleem 'n verskeidenheid redes gesoek kan word, word vir die doeleindes van hierdie artikel, by wyse van historiese terugblik, gepoog om 'n verklaring te bied vir die waargenome onvermoè van die breë taalgemeenskap om onmiddellike eienaarskap te verkry in die aktiewe bevordering van meertaligheid. Miskien lê die knoop juis hier by ouers, onderwysers en leerders en hul gesindhede daarteenoor omdat hierdie konsep van toenemende meertaligheid sterk herinner aan die 1953-BantoeOnderwyswet. Die Nasionale Party-regering van daardie tyd (in korrelasie met die bepalings van die Organisasie vir Afrika-eenheid en UNESCO) het bepaal dat aanvangsonderwys (grade 1 tot 4 ) deur medium van leerders se moedertaal moet geskied en dat daar na afloop daarvan oorgeskakel word na 'n onderrigsituasie wat deur medium van of Afrikaans, of Engels sou geskied (Kloss, 1978:41). Hierdie moedertaalbeginsel het groot ongelukkigheid in die geledere van die liberale vryheidsbewegings ontlok en is bestempel as 'n openlike poging tot verdere segmentasie en marginalisasie van alle inheemse Suid-Afrikaanse tale:

It was this set of language policies - most prominently in the form of mother-tongue instruction which united all anti-apartheid forces and large 
segments of the white liberal establishment against the Afrikaner National Party. These language policies were merely an aspect of the larger policy of apartheid (Alexander, 1989:5).

Mawasha (1995) sê die aanvaarding van dié Bantoe-Onderwyswet van 1953 het 'n reusedilemma vir die inheemse taalgroepe meegebring: indien hulle hul goedkeuring aan die wetgewing van die Nasionale Party sou verleen (al was dit in ooreenstemming met internasionale opvoedkundige beginsels), sou hulle daardeur hul instemming betoon met die beleid van afsonderlike ontwikkeling wat hulle as drakonies beleef het. Hierdie dilemma het in 1974 in intensiteit toegeneem toe daar by wyse van 'n omsendskrywe deur die toenmalige Departement van Bantoe-onderwys bepaal is dat die 50/50-beginsel van 1975 af konsekwent in die praktyk toegepas moet word (Steyn, 1980:293; Kloss, 1978:46). Dit het beteken dat alle inhoudsvakke wat aan skole binne dié departement onderrig word, om die helfte deur medium van Afrikaans en Engels aangebied moes word. Vanweë die persepsie dat Afrikaans sinoniem met die Nasionale Party-beleid was, het daar ernstige weerstand in die geledere van die Departement van Bantoe-Onderwys ontstaan wat uiteindelik in openlike weerstand op 16 Junie 1976 uitgebreek het.

Aangesien Afrikaans direk betrokke was by die 1976-opstand, het dit gelei tot 'n bedeling binne swart onderwys waar Engels die primêre medium van onderrig sou word na die jare van aanvangsonderwys deur medium van die leerder se moedertaal. Mawasha (1995) is van mening dat hierdie besluit (naamlik dat hoofsaaklik Engels die voertaal in swart skole sou wees) een van die hoofoorsake was wat daartoe gelei het dat swart sprekers van hul moedertale vervreem geraak het. Hierdie vervreemdingsproses het met die jare sodanig geïntensiveer dat swart ouers en swart leerlinge tans ook 'n pertinente voorkeur vir Engels as onderrigmedium uitspreek (Mawasha, 1996:39). Trouens, dit word algemeen aanvaar (en empiries bewys) dat taalvaardigheid in Engels bestempel word as teken van politieke, sosiale en ekonomiese bemagtiging (Mawasha, 1986).

In die lig van wat uit die onderwystaalgeskiedenis geleer kan word, word dit duidelik waarom daar weer in die land met 'n dilemma gesit word: ondanks die grondwetlike eise om die aktiewe bevordering van meertaligheid en die Langtagverslag wat sê dat slegs die aktiewe bevordering van meertaligheid sal kan lei tot ' $n$ bedeling waarin die rykdom van tale en kulture in Suid-Afrika geoptimaliseer kan word, is daar bepaalde aanduidings uit die onderwystaalgemeenskap wat getuig van die teendeel. 


\section{Persepsies en houdings teenoor meertaligheid: verslag van 'n empiriese ondersoek}

\subsection{Rasionaal}

Die doel met die volgende afdeling is om, by wyse van verslag van empiriese navorsing wat in 1996 by skole in die Noordwesprovinsie onderneem is, aan te toon watter aanduidings en rigtingwysers daar op grondvlak bestaan met betrekking tot leerders en onderwysers se houdings en persepsies teenoor meertaligheid.

Dié taaloudit is in samewerking met die Departement van Opvoeding, Rekreasie en Sport binne die grense van die Potchefstroomdistrik (een van die twaalf onderwysdistrikte in die Noordwesprovinsie) onderneem. Die navorsingsresultaat wat hier aangebied word, word as verteenwoordigend van 'n beduidende hoeveelheid leerlinge en onderwysers bestempel, hoewel daardeur nié geïmpliseer word dat dit waar is van alle skoolgemeenskappe in die land nie.

Die skole wat by die ondersoek betrek is, kom uit die breë onderwysspektrum en verteenwoordig die totale navorsingspopulasie en van alle skole. Op grond van ewekansige steekproefneming is $8 \%$ van die 200 hoër- en middelbare skole geselekteer om as navorsingspopulasie op te tree. Aangesien die navorsing hoofsaaklik by plattelandse skole uitgevoer is, is geen skool met Engelssprekende leerlinge hierby betrek nie

Vraelyste is by elkeen van die gekose skole aan $10 \%$ van die senior leerlinge versprei waardeur kwantitatiewe data bekom is ${ }^{3}$. Nadat dié vraelys afgehandel is, is $10 \%$ van die respondente weer op ewekansige wyse geselekteer. Met hierdie respondente is gesprek gevoer aan die hand van 'n gestruktureerde vraelys sodat kwalitatiewe data bekom kan word. Gesprek is ook met die betrokke taalonderwysers gevoer sodat hulle persepsies, verwagtinge en probleme oor die onderrig van hul vakke duidelik kon word. Uitgebreide gesprek is ook met die vakadviseurs vir Afrikaans, Engels en Tswana in die Potchefstroomdistrik gevoer.

Die talewerklikheid in die onderwysgeledere in die Noordwesprovinsie word eerstens weergegee vir 'n behoorlike kontekstualisering van die navorsing (Noordwes-Onderwysdepartement, 1996):

- Die totale skoolgaande bevolking in die provinsie is amper 1 miljoen. Die ouderdom van die skoolgaande bevolking wissel van onder 7 jaar tot 22 jaar.

3 Hoewel leerlinge 'n keuse kon uitoefen ten opsigte van die taal waarin hulle die vraelyste kon invul, het die oorgrote meerderhcid verkies om dit deur medium van Engels te doen. 
- Meer as $65 \%$ van die leerlinge gebruik Tswana as huistaal. Dit vorm die grootste huistaal onder die skoolgaande bevolking in die Noordwesprovinsie. Hoewel al die ander Suid-Afrikaanse tale ook as huistale in die provinsie gebruik word, is hulle almal minderheidstale. Interessante syfers met betrekking tot die huistaalverspreiding van leerlinge is die volgende: $7.5 \%$ is Afrikaanssprekend; $6 \%$ is Xhosasprekend; $5.9 \%$ is Sothosprekend en $0.9 \%$ is Engelssprekend.

- Met betrekking tot die doseer van die verskillende taalvakke, bied 654 sekondêre skole in die provinsie Afrikaans (tweedetaal) aan; Engels (tweedetaal) word deur 650 skole en Tswana (eerstetaal) deur 631 skole aangebied. Engels (eerstetaal) word deur 47 skole aangebied, terwyl Afrikaans (eerstetaal) deur 43 skole aangebied word.

- Met betrekking tot die hoeveelheid leerlinge wat vir die verskillende taalvakke ingeskryf is, lyk die statistiek soos volg: 143290 leerlinge is ingeskryf vir Engels (tweedetaal); 139434 vir Afrikaans (tweedetaal) en 135256 vir Tswana (eerstetaal).

\subsection{Navorsingsresultate}

\subsubsection{Kwantitatlewe data}

Die volgende tabelle verteenwoordig die kwantitatiewe data wat tydens die verwerking van die resultate na vore gekom het: Tabel 1 verteenwoordig die respondente se ouderdomsverspreiding, Tabel 2 die taal waaraan hulle voorkeur gee as skoolvak, Tabel 3 die huistaalverdeling en Tabel 4 die onderrigmedium waardeur hulle skoolonderrig ontvang.

\section{Iabel 1: Respondente se ouderdom}

\begin{tabular}{|l|l|l|l|l|}
\hline 12 jaar & $13-15$ jaar & $16-18$ jaar & $19-20$ jaar & $21+$ jaar \\
\hline $2 \%$ & $24 \%$ & $50 \%$ & $11 \%$ & $13 \%$ \\
\hline
\end{tabular}

Iabel 2: Gunstelingtaalvak

\begin{tabular}{|l|r|}
\hline Afrikaans & $16.9 \%$ \\
\hline Engels & $64.7 \%$ \\
\hline Engels \& Afrikaans & $0.5 \%$ \\
\hline Engels \& Tswana & $1 \%$ \\
\hline Sotho & $2.5 \%$ \\
\hline Tswana & $10 \%$ \\
\hline Xhosa & $0.5 \%$ \\
\hline Hou nie van enige taalvak nie & $3.5 \%$ \\
\hline
\end{tabular}


Dit is uit die voorafgaande tabel duidelik dat leerders 'n positiewe houding jeens Engels as skoolvak openbaar.

\section{Tabel 3: Respondente se huistale}

\begin{tabular}{|l|r|}
\hline Afrikaans & $23.5 \%$ \\
\hline Afrikaans, Engels & $4.5 \%$ \\
\hline Afrikaans, Engels, Tswana & $1 \%$ \\
\hline Afrikaans, Engels, Tswana, Xhosa & $0.5 \%$ \\
\hline Sotho & $12 \%$ \\
\hline Sotho, Afrikaans & $0.5 \%$ \\
\hline Sotho, Engels & $1.5 \%$ \\
\hline Tswana & $34.5 \%$ \\
\hline Tswana, Afrikaans & $3 \%$ \\
\hline Tswana, Engels & $3 \%$ \\
\hline Tswana, Sotho & $3 \%$ \\
\hline Tswana, Xhosa & $2.5 \%$ \\
\hline Tswana, Xhosa, Engels & $1 \%$ \\
\hline Tswana, Xhosa, Sotho & $0.5 \%$ \\
\hline Xhosa & $6.5 \%$ \\
\hline Xhosa, Sotho & $1.5 \%$ \\
\hline Xhosa, Sotho, Engels & $0.5 \%$ \\
\hline Zulu & $0.5 \%$ \\
\hline
\end{tabular}

By 'n nadere ontleding van die tabel blyk dat $23 \%$ respondente aangedui het dat hulle tuis'n meertalige situasie het.

\section{Tabel 4: Onderrlgmediums}

\begin{tabular}{|l|r|}
\hline Engels & $64.9 \%$ \\
\hline Afrikaans & $27.7 \%$ \\
\hline Engels, Afrikaans, Tswana & $7.4 \%$ \\
\hline
\end{tabular}

Hoewel geeneen van die respondente aangedui het dat Engels die huistaal is nie, ontvang ongeveer $65 \%$ van hulle hulle sekondêre onderrig deur medium van Engels. Die voorafgaande tabel dui ook aan dat meertaligheid as lingua franca in die klaskamerpraktyk aangewend kan word. 


\subsubsection{Kwalitatiewe data}

Kwalitatiewe data is versamel aan die hand van oop vrae in die vraelys, sowel as deur die gestruktureerde onderhoud wat met $10 \%$ van die totale hoeveelheid respondente gevoer is.

\subsubsection{Houding en persepsies teenoor Engels}

Die volgende redes is as motivering deur die respondente $(n=202)$ aangevoer vir dit wat hulle houding teenoor Engels motiveer:

- $31.2 \%$ skryf hulle positiewe ingesteldheid teenoor Engels toe aan die feit dat die vak op ' $n$ interessante en kreatiewe wyse onderrig word.

- $18.6 \%$ sê Engels gee toegang tot tersiêre onderwysgeleenthede en ekonomiese bemagtiging.

- $16.5 \%$ se positiewe ingesteldheid setel in die feit dat Engels 'n bindingstaal in die Suid-Afrikaanse konteks is omdat dit die meeste mense se tweede taal is.

- $10 \%$ sê hulle is nie positief teenoor Engels nie, omdat dit 'n moeilike taal is om aan te leer.

- $9.5 \%$ sê weer hulle voortdurende blootstelling aan die taal maak dit vir hulle maklik om die taal baas te raak.

- $7.2 \%$ sê dat Engels ' $n$ ideale teikentaal is omdat hulle die Engelse kultuur aantreklik vind.

- $7 \%$ gee aanduiding dat die internasionale status van Engels ' $n$ bemagtigende uitwerking op alle sprekers van Engels het.

Dit word uit die voorafgaande bespreking duidelik dat die oënskynlike instrumentele waarde wat respondente aan Engels koppel 'n vername rol speel in hulle persepsie teenoor die taal. Daarby is dit insiggewend dat die wyse waarop die vak op skool aangebied word 'n belangrike bydrae vorm in respondente se houding teenoor die taal.

Die feit dat respondente aandui dat hulle dit nie moeilik vind om Engels aan te leer nie, verdien verdere kommentaar - veral in die lig van onlangse navorsing wat die Raad vir Geesteswetenskaplike navorsing in dié verband onderneem het (Beeld, 10 Januarie 1997). Hiervolgens is bevind dat, hoewel leerders in graad 5 ten minste 5000 Engelse woorde moet ken om die vakinhoude in Engels te kan baasraak, die woordeskat van sommige graad 4-leerlinge slegs 800 Engelse woorde is. 


\subsubsection{Persepsie en houding teenoor die ander streekstale}

Met betrekking tot die respondente $(n=145)$ se houding en persepsies teenoor die inheemse tale (Tswana, Suid-Sotho en Xhosa) word dit duidelik dat leerders lojaal teenoor die taaleie is omdat die persepsie bestaan dat hierdie tale as draers van kulturele eiegoed optree.

Die volgende gegewens illustreer in die besonder dat

- hoewel $68.2 \%$ positief voel teenoor die nuutverwerfde amptelike status van inheemse tale, hierdie status hoofsaaklik as van blote simboliese waarde beleef word;

- $13.2 \%$ positief voel teenoor die inheemse tale omdat dit maklike vakke is om te slaag;

- $9.2 \%$ aandui dat inheemse tale as teikentale in streeksverband funksioneer en daarom is daar ' $n$ positiewe gevoel daarteenoor;

- $8.9 \%$, ten spyte van die feit dat hulle positief ingestel is teenoor die inheemse tale, nie oortuig is van die waarde van hierdie tale vir administratiewe en akademiese doeleindes nie.

Met betrekking tot respondente $(n=145)$ wat nié moedertaalsprekers van Afrikaans is nie, het dit duidelik geword dat hulle houding teenoor die taal in die volgende motiverings setel:

- $26 \%$ beskou Afrikaans as 'n moeilike taal om baas te raak.

- $23.5 \%$ geniet die onderrig van Afrikaans as skoolvak.

- $21 \%$ erken die instrumentele waarde van Afrikaans op die platteland en sien dit, vanweë ekonomiese oorwegings, as 'n teikentaal.

- $20.5 \%$ twyfel weer aan die pragmatiese waarde van Afrikaans in 'n verstedelikte omgewing.

- $7.5 \%$ sê hulle kan nie Afrikaans praat nie.

- $1.5 \%$ dui aan dat daar 'n band bestaan tussen Afrikaans en die vorige apartheidsbedeling en sê dat dit die rede is waarom hulle negatief teenoor die taal ingestel is. 


\subsubsection{Samevattend: indrukke van die houdings en persepsies van die onderwyssektor teenoor die streekstale in die Noordwesprovinsie}

Die empiriese navorsing waarop hierdie artikel gebaseer is, gee bewys van wat algemeen onder die taalgemeenskappe in Suid-Afrika leef: die praktiese vergestalting van veeltaligheid lê hoofsaaklik in die toekenning van simboliese amptelike status aan die inheemse tale, terwyl dit gewens is om Engels as werksen administrasietaal oor die bree spektrum te gebruik. Trouens, dit blyk baie duidelik dat respondente selfs nie voel dat hul gebruik van Engels 'n bedreiging inhou vir die voortbestaan van die inheemse tale nie. Die voorkeur aan Engels dwarsoor die politieke spektrum, die handelswêreld, die vermaaklikheidswêreld én die onderwyssektor (soos bewys uit dié navorsing) bewys waarskynlik dat die Suid-Afrikaanse samelewing nie daartoe kom om, in dieselfde mate as wat dit in die Grondwet na vore kom, die veeltaligheidsbeginsel na te jaag nie.

\section{Sintese: 'n beoordeling van dle tendense rondom en uitdaglngs aan meertaligheld in die Suid-Afrlkaanse bestel}

Hoewel dit belangrik is om kennis te neem van die feit dat daar nie noodwendig 'n korrelasie bestaan tussen wat mense sê hulle oortuigings is, én dit waarvan hulle in werklikheid oortuig is nie, is dit belangrik dat taalbeplanners kennis moet neem van wat mense dink oor taalsake.

Dit is uit die navorsing wat onderneem is duidelik dat daar ' $n$ teenstrydigheid bestaan in die persepsies en houdings teenoor inheemse tale omdat respondente oorweldigend positief voel teenoor die amptelike status van dié tale, maar Engels (en in ' $n$ mindere mate Afrikaans) verkies vir administratiewe en ekonomiese doeleindes. Die teenstrydigheid tussen houdings teenoor kulturele erfgoed en persoonlike bemagtiging word duidelik gemaak in die waarneming dat inheemse tale as draers van sosio-kulturele eiegoed bestempel word terwyl hulle nie hooggeskat word indien daar na persoonlike, akademiese en ekonomiese bemagtiging gestreef word nie. Dit blyk vervolgens dat dié voorkeur gemotiveer is op grond van pragmatiese, eerder as op grond van ideologiese beweegredes.

Dit is juis wanneer hierdie oennskynlike teenstrydige houdings teenoor tale geïnterpreteer word teen die agtergrond van die Suid-Afrikaanse geskiedenis, dat dit duidelik word waarom taalbeplanners en beleidmakers daarvan moet kennisneem. Hoewel dit duidelik is dat die nasionale sosio-politieke transformasieproses uitgeloop het op algemene trots en lojaliteit teenoor inheemse tale, kon dié tale tot nog toe nog nie daarin slaag om op teen-ideologiese wyse teenoor Engels en Afrikaans op te tree nie. Daarom gebeur dit dat, ten spyte van die amptelike 
status van inheemse tale, Engels besig is om sy de facto-posisie as bemagtigingsinstrument te konsolideer.

Dit word dus hienuit duidelik dat die status en prestige van inheemse tale - wat onontbeerlik is vir taalgemeenskappe se houdings teenoor tale (Giles et al., 1987: 585) - slegs bevestig kan word indien funksionele meertaligheid in Suid-Afrika nagestreef word. Dit kom daarop neer dat álle Suid-Afrikaanse tale bevorder moet word vir sowel administratiewe en werksdoeleindes, as vir die feit dat hulle optree as draers van sosio-kulturele eiegoed. Cooper (1989:167) sê in hierdie verband dat daar 'n dinamiese interaksie moet bestaan tussen die doelwitte van 'n taalbeleid en die kulturele en sosiale klimaat waarin die beleid geïmplementeer moet word.

\section{Gevolgtrekking}

Hierdie artikel se aanname was dat, ten spyte van grondwetlike beginsels en amptelike middele waardeur meertaligheid in die Suid-Afrikaanse samelewing gevestig moet word, die praktiese vergestalting daarvan skipbreuk ly. Die hipotese grondliggend tot hierdie artikel was of dat die meertalige beleid bloot om politiese korrektheidsbeginsels daargestel is, of dat daar vanuit die maatskappy nie-amptelike druk bestaan om die meertaligheidsbeginsels in die praktyk te omseil.

Omdat taalnavorsing in die onderwyssektor, volgens Edwards (1994:11), geleenthede bied om die amptelike en nie-amptelike dryfvere na te gaan, is empiriese navorsing in onderwysgeledere onderneem om na te gaan watter oorsake bepaal kan word vir die diskrepans tussen die de jure en de-factotaalsituasies in Suid-Afrika. Dit het hieruit duidelik geword dat swart tieners in die Noordwesprovinsie hul inheemse tale hoogskat, maar dat hoofsaaklik Engels verkies word as akademiese, administratiewe, ekonomiese en persoonlike bemagtigingsinstrument.

Dit word ten slotte hieruit duidelik dat die taalbeplanningsuitdagings wat uit dié situasie af te lei is, eerstens dui op 'n sensitiwiteit vir die sosio-kulturele konteks waarin ' $n$ taalbeleid gemiplementeer moet word. Tweedens word dit duidelik dat funksionele meertaligheid nie nagestreef $k a n$ word indien daar nie werklik 'n behoefte aan meertalige vaardighede in gemeenskappe bestaan nie. Dit beteken dat die taalartikels in die grondwet slegs geoptimaliseer kan word indien inheemse tale as onontbeerlike kommunikasiemiddele vir administratiewe, akademiese, regs- en mediadoeleindes in die Suid-Afrikaanse samelewing bestempel word.

Die kwessie word egter bemoeilik in die lig van Breton se uitspraak dat elke taal ingebed is in menswees (Breton, 1996:164). Dit bring mee dat taalbeplanning nie 
gesien kan word as 'n blote tegniese aktiwiteit waarin besluite geneem en deurgevoer word sonder om die sosio-kulturele eiegoed wat in spraakgemeenskappe ingebed lê, sowel as spraakgemeenskappe se persepsies oor die prestige en status van tale, te verreken nie.

\section{Bibllografie}

Alexander, N. 1989. The language question Critical Choices for South African Society: 12 , June.

Beukes, A.-M. 1996. Language in the public service. In: Language Plan Task Group. Towards a national language plan for South Africa. Pretoria : State Language Service. p. 153-179.

Breton, R. 1996. The dynamics of ethnolinguistic communities as the central factor in language policy and planning. International Journal of the Sociology of Language, 118:163-179.

Buthelezi, Q. 1996. Language equity. In: Language Plan Task Group. Towards a national Ianguage plan for South Africa. Pretoria : State Language Service. p. 41-66.

Cooper, R.L. 1989. Language planning and social change. Cambridge : Cambridge University Press.

Edwards, J. 1994. Multilingualism. London : Routledge.

Giles, H., Hewstone, M., Ryan, E.B., Johnson, P. 1987. Research on language attitudes. In: Ammon U., Dittmar, N. \& Mattheier, K.J. (eds.) Sociolinguistics: An international handbook of the science of language and society. Berlin : De Gruyter. p. 585-597.

Kloss, H. 1978. Problems of language policy in Soulh Africa Wien : Wilhelm Braumüller.

Langtag

kyk

Language Plan Task Group

Language Plan Task Group. 1996a. Towards a national language plan for South Africa. Pretoria : State Language Services.

Language Plan Task Group. 1996b. Overview, recommendations and executive summary from the Final Report of the Language Plan Task Group. Pretoria : State Language Services.

Mawasha, A 1995. The role of English in education in the new South Africa. Voordrag gelewer by die taalkonferensie oor "Eleven Official Languages in South Africa: The implications of South Africa's Language Policy on the Teaching of Languages". Georganiseer deur die Rainbow Communications Group. 23-25 April 1995. Johannesburg.

Mawasha, A.L 1986. Adopting the son of the conqueror. English in Africa. S.T. Plaatje Memorial Lecture. Mafikeng : University of Bophutatswana.

Mawasha, A.L. 1996 Teaching African languages to speakers of other South African languages: operationalising the new democratic language policy in South Africa. Journal for Language Teaching, 30(1):35-41.

Noordwes-Provinsie. Dept. van Onderwys, Sport en Rekreasie. 1996. Pass rates, student flows and profile graphs based on 1995 estimates. Ongepubliseerde, interne verslag. Mmabatho.

Steyn, J.C. 1980. Tuiste in eie taal. Kaapstad : Tafelberg.

Steyn, J C. 1996. Die taalklousule in die nuwe Grondwet: moontlike toepassing. Tydskrif vir Geesteswetenskappe, 36(4):272-283, Desember. 
Tollefson, 1981. Decentralized and centralized language planning. Language Problems and Langruage Planning, 5(2): 175-188

Verhoef, M. 1996. Die taalsituasie in die onderwys van die Noordwesprovinsie: tendense en geleenthede in die aanloop tot 'n nuwe bedeling. Ongepubliseerde verslag. Vanderbijlpark : Potchefstroomse Universiteit vir Christelike Hoër Onderwys. 